\title{
On a high-speed hearing measurement considering the age of both ears
}

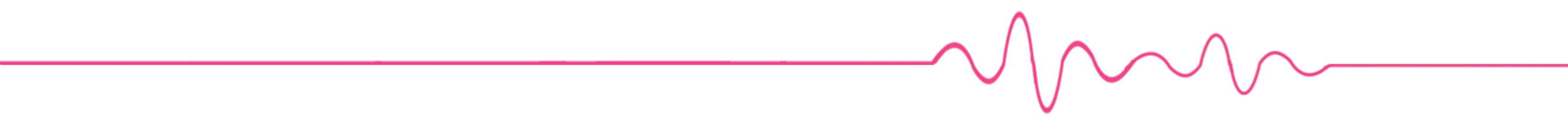

\author{
Seong-Geon Bae ${ }^{1}$ and Myungjin Bae ${ }^{2}$
}

Div. of Comput. Media Information Eng., Kangnam University

Information and Telecomm., Soongsil University 


\section{Abstract}

In this paper, we proposed a high-speed measurement method that can easily and quickly self-measure both ear hearing damage through an APP of a smart-phone. In this method, nine pure tones that are age-compensated for each voice subband are alternately heard in both ears, thereby self-identifying their own hearing damage at high speed.

When 18 tone pulses were heard for 27 seconds per person, 1 out of 12 subjects was identified as suspected of partial hearing damage. And when the test subjects were informed of the hearing determination method for the number of hearings, the participants themselves immediately determined whether their hearing was damaged. 


\section{I . Introduction}

In order for humans to lead a happy life, they must not only have no disease, but also enjoy the joy by enriching the five senses. But statistically, Koreans live in pain for an average of 18.5 years until their physical functions age and die at an average age of 83.5 years.

In order to live a happy life, you will need to find and treat unhealthy parts early through regular medical checkups. The hearing that has once deteriorated, especially amid the threat of noise, does not recover. It is common for hearing to deteriorate from high frequency bands as the body ages.

In this study, we propose a self-hearing measurement method of the two ear frequencyspecific gain-compensated Voice sub-band, which allows us to immediately measure hearing loss in both ears by a simple app without being examined in a hospital. Through this, the purpose is to create a living environment in which one can protect one's hearing by easily measuring whether one has partial hearing loss. 


\section{Structure of auditory organs}

The detection and recognition of sound in our human body is called the auditory organ.

The vibration of the eardrum is amplified by the scavenging bone and transmitted to the cochlea. The cochlea analyzes the sound vibrations received and transmits them to the brain.

Figure 1 shows the structure of the auditory organs and cochlear tubes. The cochlea recognizes the high-mainstream wave from the entrance and the more it gets to the back, the more it recognizes the cursing wave.

The right side of Figure 1 shows a length of about $3.3 \mathrm{~cm}$ when the cochlea is extended, and the interior is filled with water in the molar cells, and if the hair of the molar is lost due to the loud sound outside, the noise-induced hearing loss will occur and the sound will not be recognized well.
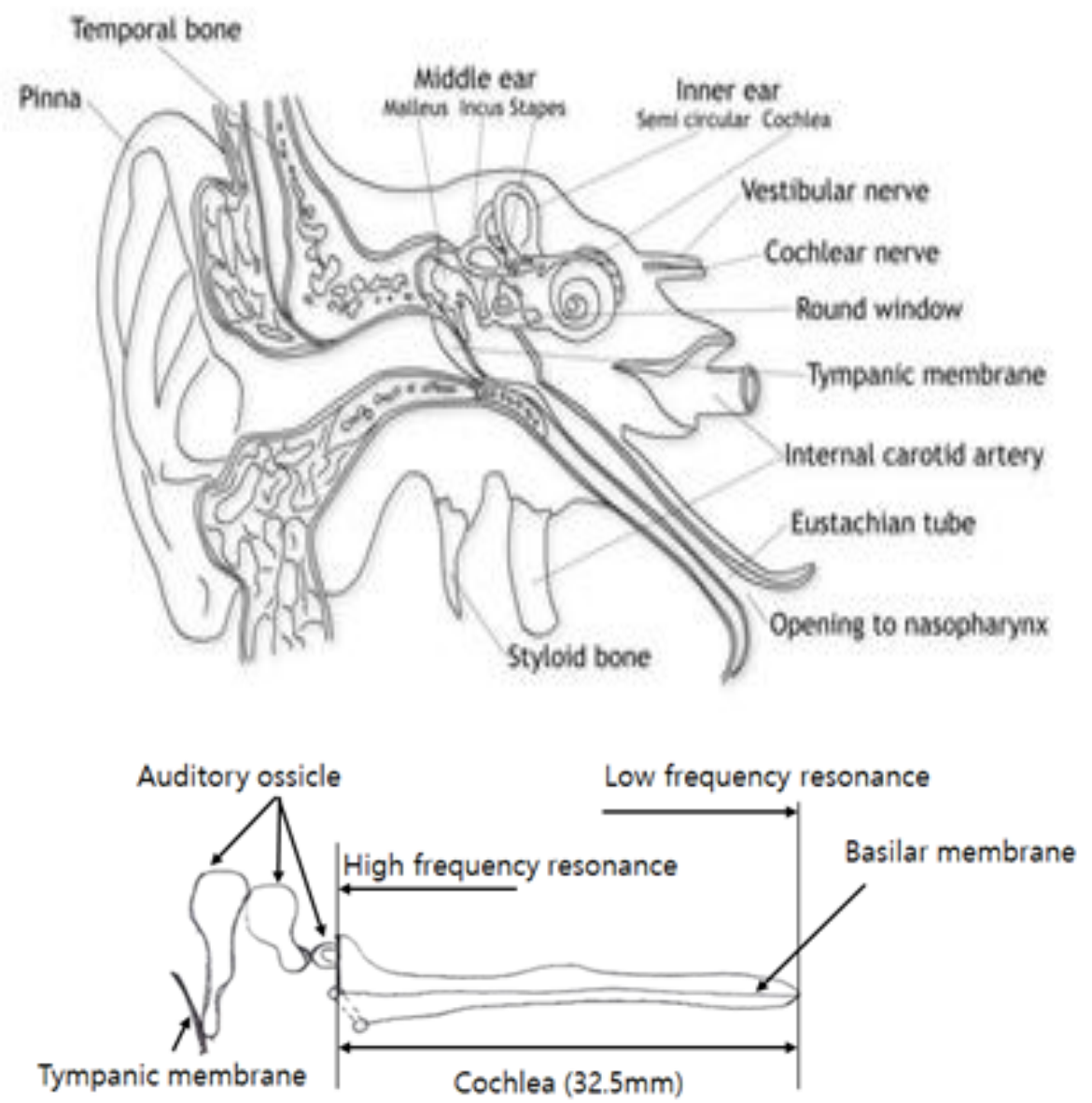

Figure 1. Hearing Organ and Cochlear Model. 


\section{Structure of auditory organs}

Figure 2 shows the distribution of resonant frequencies along the length of the cochlear tube, i.e. the distance of the basal membrane, the deeper the distance of the basal membrane, the more likely it is to detect a cursing wave.

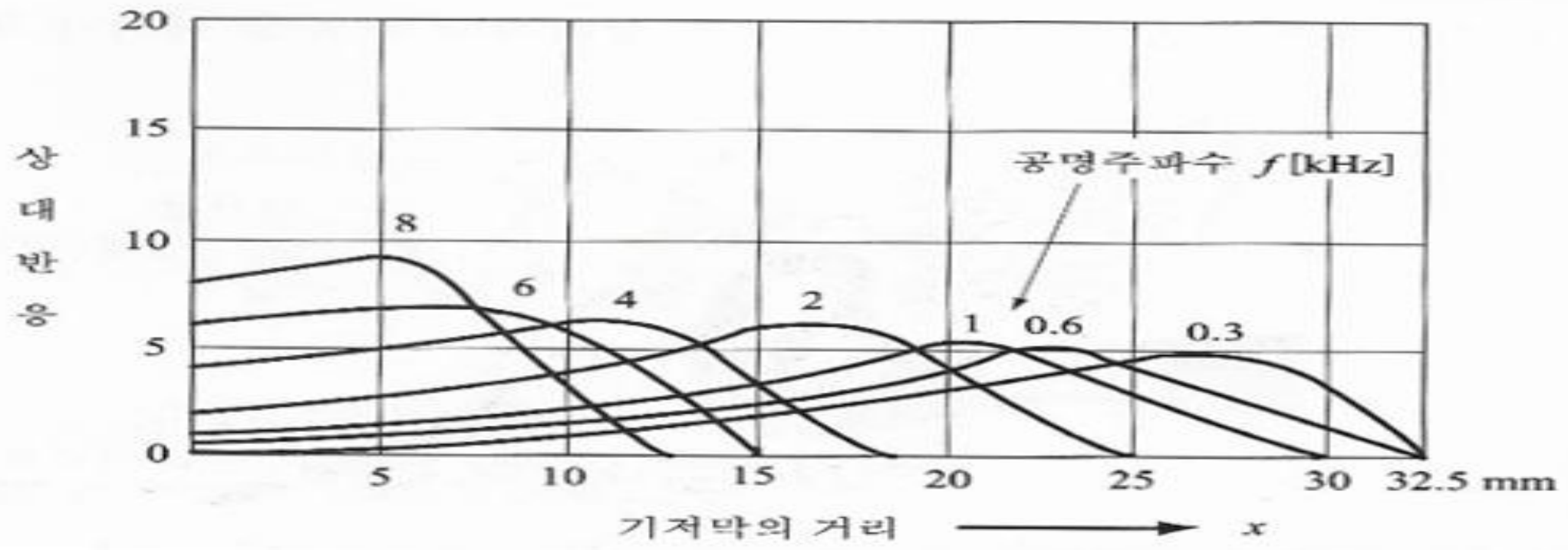

Figure 2. Distribution of resonant frequencies according to the distance of the basement membrane. 


\section{II-1. Characteristics of voice signals}

A person's hearing frequency is known to be between 20 and 20,000 Hz. However, a person's voice is below $8,000 \mathrm{~Hz}$. Generally, a person's words are expressed in frequency components ranging from 200 to $8000 \mathrm{~Hz}$.

A person's vocal cords move by air pushed in from the lungs, and are controlled to tremble by the tension of the vocal cords.

Fundamental frequency exists between 50 and $250 \mathrm{~Hz}$ for men and 120 to $500 \mathrm{~Hz}$ for women.

Fundamental Frequency depends on physical structure, lifestyle, etc. and changes under the influence of emotion or various circumstances.

Figure 3 shows the speech wave in the time domain, with the speech organs moving according to what is intended to be expressed, and different types of sound waves fluctuating over time.

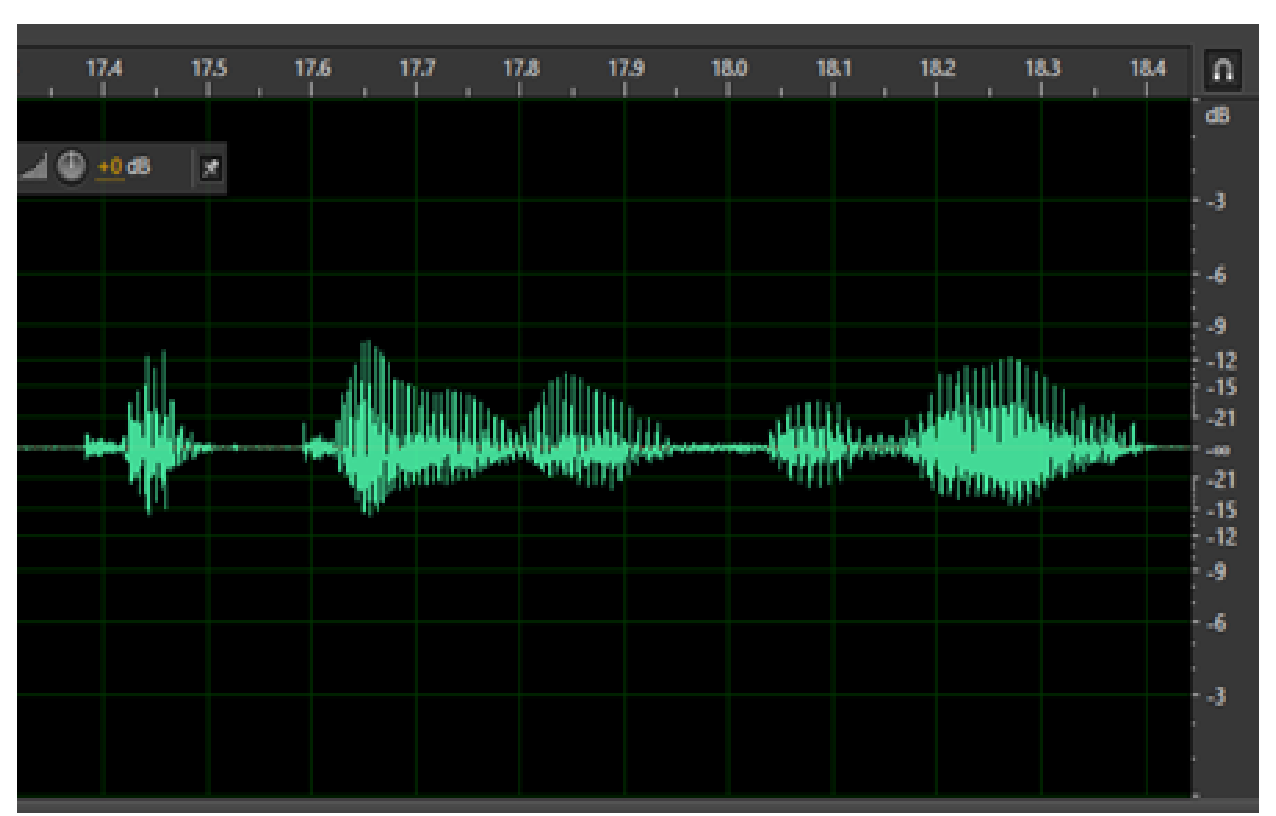

Figure 3. A speech signal waveform. 


\section{II-1. Characteristics of voice signals}

Figure 4 shows the component distribution by frequency in the frequency spectrum of the voice signal.

In the frequency domain, the location and size of the resonant peak formant changes as the vocalization changes, and the changing characteristics are recognized and understood verbally by the auditory institution.

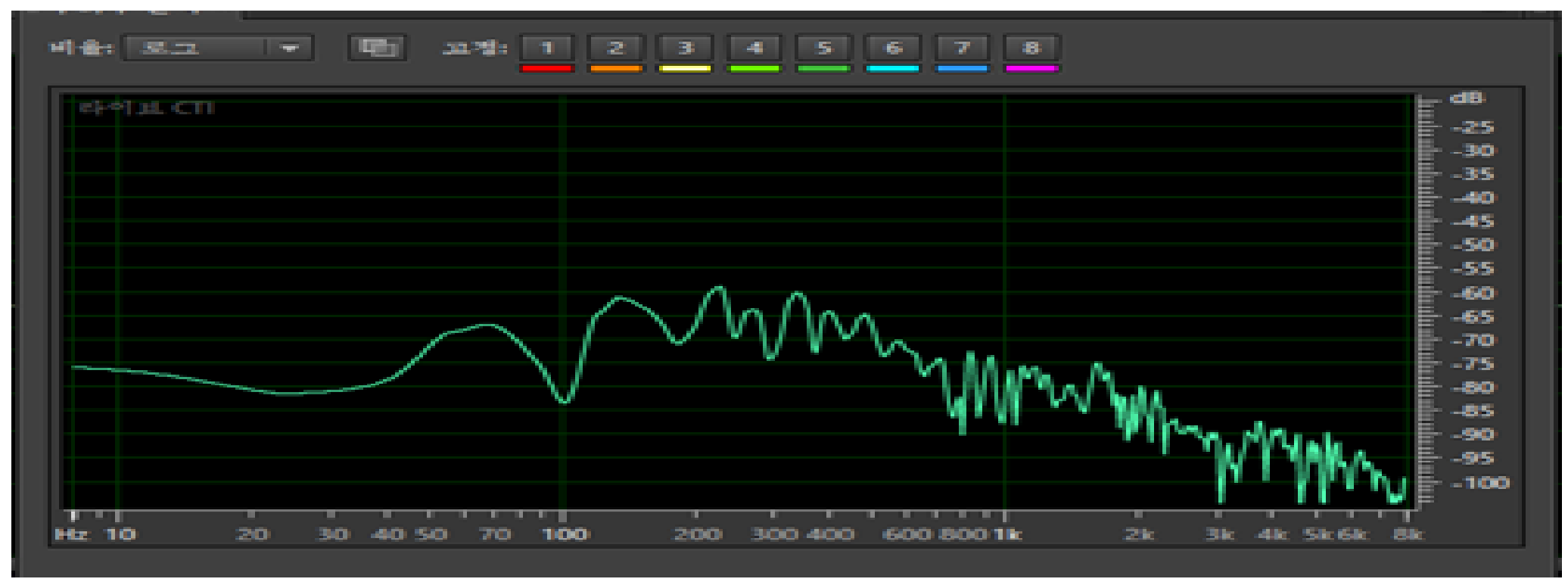

Figure 4. A speech signal spectrum. 


\section{Conventional auditory measurement method}

Methods of hearing measurement include pure sound hearing test, impedance hearing test, promissory note hearing test, and youth hearing test, the most common of which is pure sound hearing test.

The pure sound test is a method of sounding the pure tone for each frequency for $250 \mathrm{~Hz}$ to $8 \mathrm{KHz}$, which is mainly used in everyday conversations, as shown in Figure 5, and measuring whether the sound is audible well.

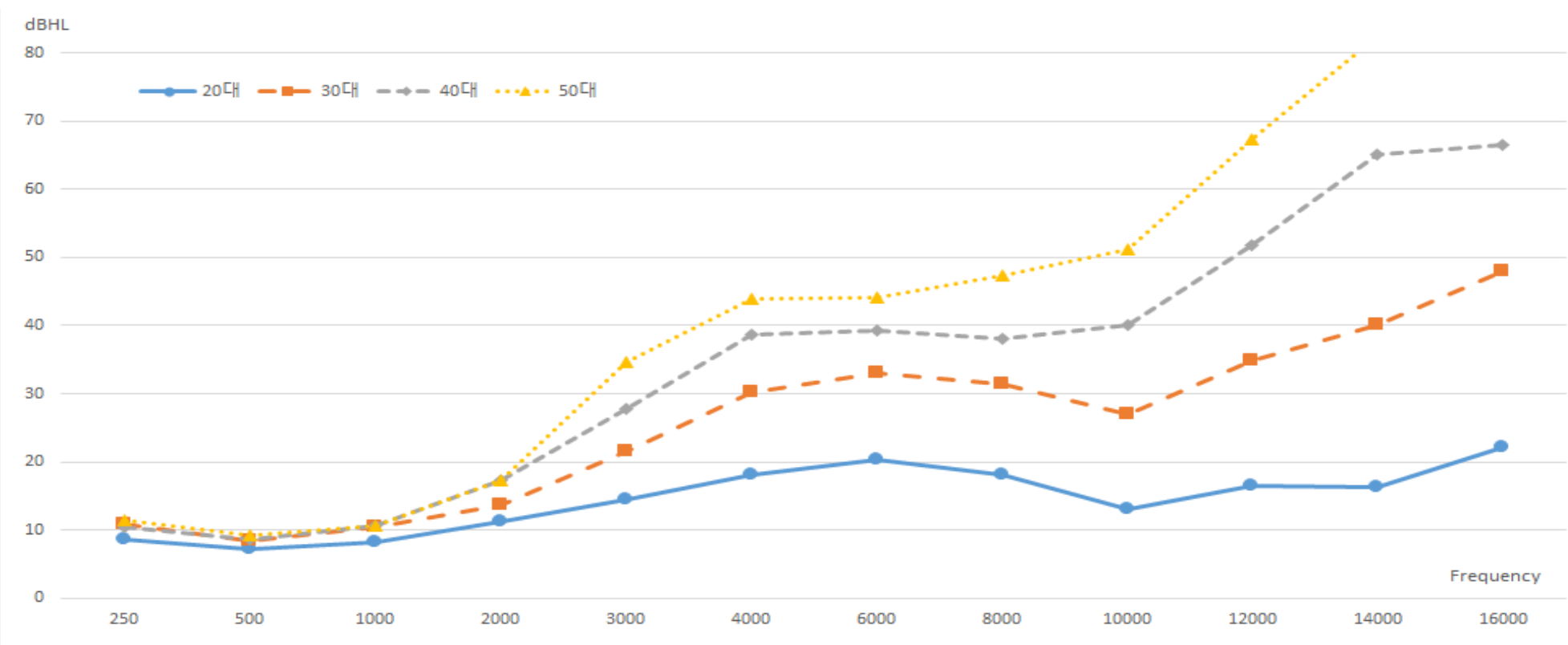

Figure 5. Average hearing threshold by age group. 


\section{Conventional auditory measurement method}

However, it is difficult to know whether the hearing is damaged or not, as most hospitals do not have hearing tests at the normal level of the conversation, and they judge it to be normal.

In addition, conventional pure sound hearing tests are costly and time consuming because hearing verification for multiple frequency components is passively handled. 


\section{Self-hearing measurement method with gain-compensated voice sub-band}

In this paper, we propose a pure sound hearing measurement method for a voice sub-band-specific self-hearing measurement method that simultaneously measures both ears.

Figure 6 shows an estimate of purity perceived by age groups in Voice subband. In this picture, the sound level is higher than the hearing threshold for each age group, so it can be confirmed that it is a pure tone that can be recognized by the ear.
dBHL

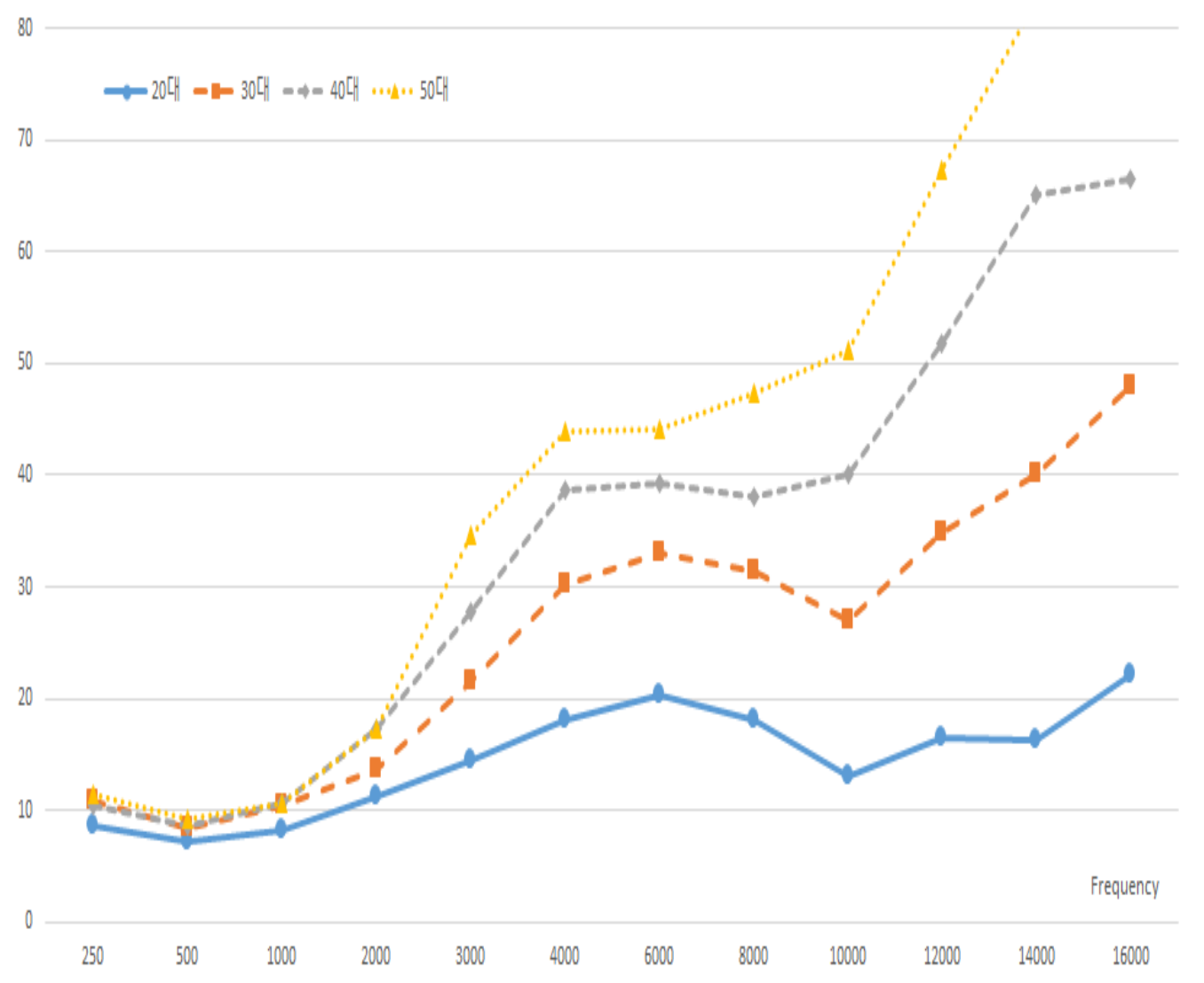

Figure 6 . Average hearing threshold by age group. 


\section{Self-hearing measurement method with gain-compensated voice sub-band}

Figure 7 shows uniform blue-dot line recognizable by age group in the subband of the auditory domain.

What is clear here, however, is that at $3 \mathrm{KHz}$ or higher, the sound tone of the partial force is not well understood by age groups, even if hearing is normal to a degree proportional to the loudness curve.

Therefore, in this paper, the level was compensated and told by +15 $\mathrm{dB} /$ octave for pure ton for measurement from 2.5 to $8.0 \mathrm{kHz}$.

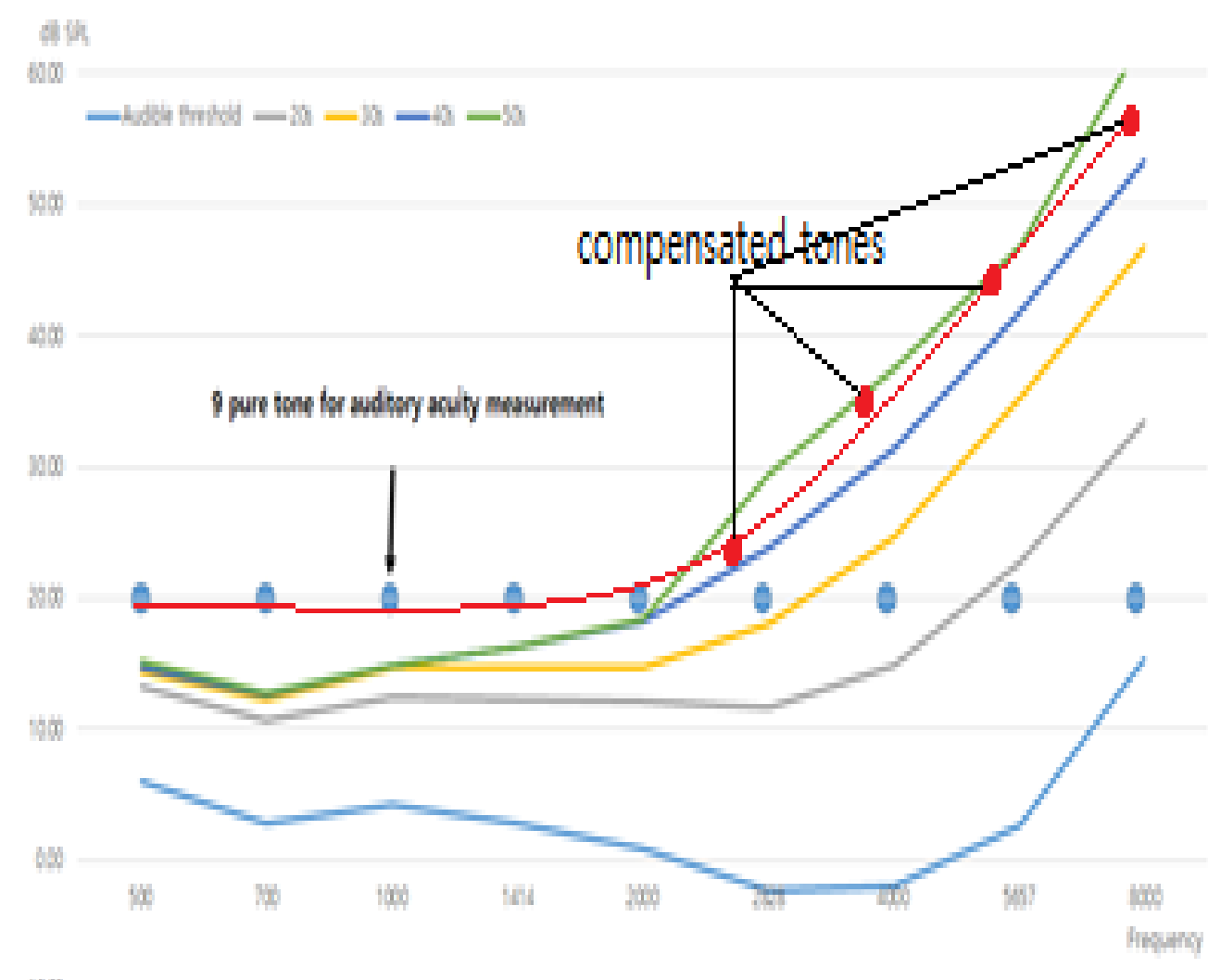

Figure 7. Expected value of voice sub-band pure tone perception by age group. 


\section{Self-hearing measurement method with gain-compensated voice sub-band}

In order to measure partial hearing damage, the method of separating sounds and counting the number of sounds heard is applied as shown in Table 1. The sound source was nine pure tones that increased the frequency to Melscale from 500 to $8000 \mathrm{~Hz}$.

For example, if subjects with normal hearing were given pure tones in the auditory field, as shown in Table 1, the total number of pulse tones heard in one second intervals would be nine, but subjects with hearing impairments would hear no more than eight pulse tones.

Table 1. Proposed voice sub-band pure tone arrangement of single ear.

\begin{tabular}{|l|l|l|l|l|l|l|l|l|l|}
\hline Tone Freq. & 500 & 700 & 1000 & 1414 & 2000 & 2828 & 4000 \\
$\mathrm{~Hz}$ & $\mathrm{~Hz}$ & $\mathrm{~Hz}$ & $\mathrm{~Hz}$ & $\mathrm{~Hz}$ & $\mathrm{~Hz}$ & $\mathrm{~Hz}$ & $5657 \mathrm{~Hz}$ & $\begin{array}{l}8000 \\
\mathrm{~Hz}\end{array}$ \\
\hline Tone No. & 1 & 2 & 3 & 4 & 5 & 6 & 7 & 8 & 9 \\
\hline
\end{tabular}




\section{Self-hearing measurement method with gain-compensated voice sub-band}

The pulse tones are now arranged separately from side to side as shown in Table 2 to measure the hearing in both ears at the same time. Pulse tones were spaced in seconds, followed by a tone in the left ear and a tone in the right ear one second later, repeating the nine-segment band in three seconds intervals for each band.

Table 2. Proposed voice sub-band pure tone arrangement of both ears.

\begin{tabular}{|c|c|c|c|c|c|c|c|c|c|}
\hline & 500 & 700 & 1000 & 1414 & 2000 & 2828 & 4000 & 5657 & 8000 \\
$\mathrm{~Hz}$ & $\mathrm{~Hz}$ & $\mathrm{~Hz}$ & $\mathrm{~Hz}$ & $\mathrm{~Hz}$ & $\mathrm{~Hz}$ & $\mathrm{~Hz}$ & $\mathrm{~Hz}$ & \\
\hline L-ear & 1 & 2 & 3 & 4 & 5 & 6 & 7 & 8 & 9 \\
\hline R-ear & 9 & 8 & 7 & 6 & 5 & 4 & 3 & 2 & 1 \\
\hline
\end{tabular}




\section{Experimental and Results}

In this paper, a self-hearing experiment of both ears was conducted on 12 men and women in their teens and 40s by listening to the compensated pulse tone of the audio band proposed in this paper. Subjects are people who normally have no difficulty communicating and think that hearing is fine.

As shown in Table 2, 18 pure tones (500$8000 \mathrm{~Hz}$ ) with frequency-specific gains compensated were generated left and right, played for 27 seconds, and ordered to count the number of pulse tones heard. At first, I didn't understand the number of pulse tones I heard, so I tried to measure them in earnest after having them experience the pulse tone in advance.

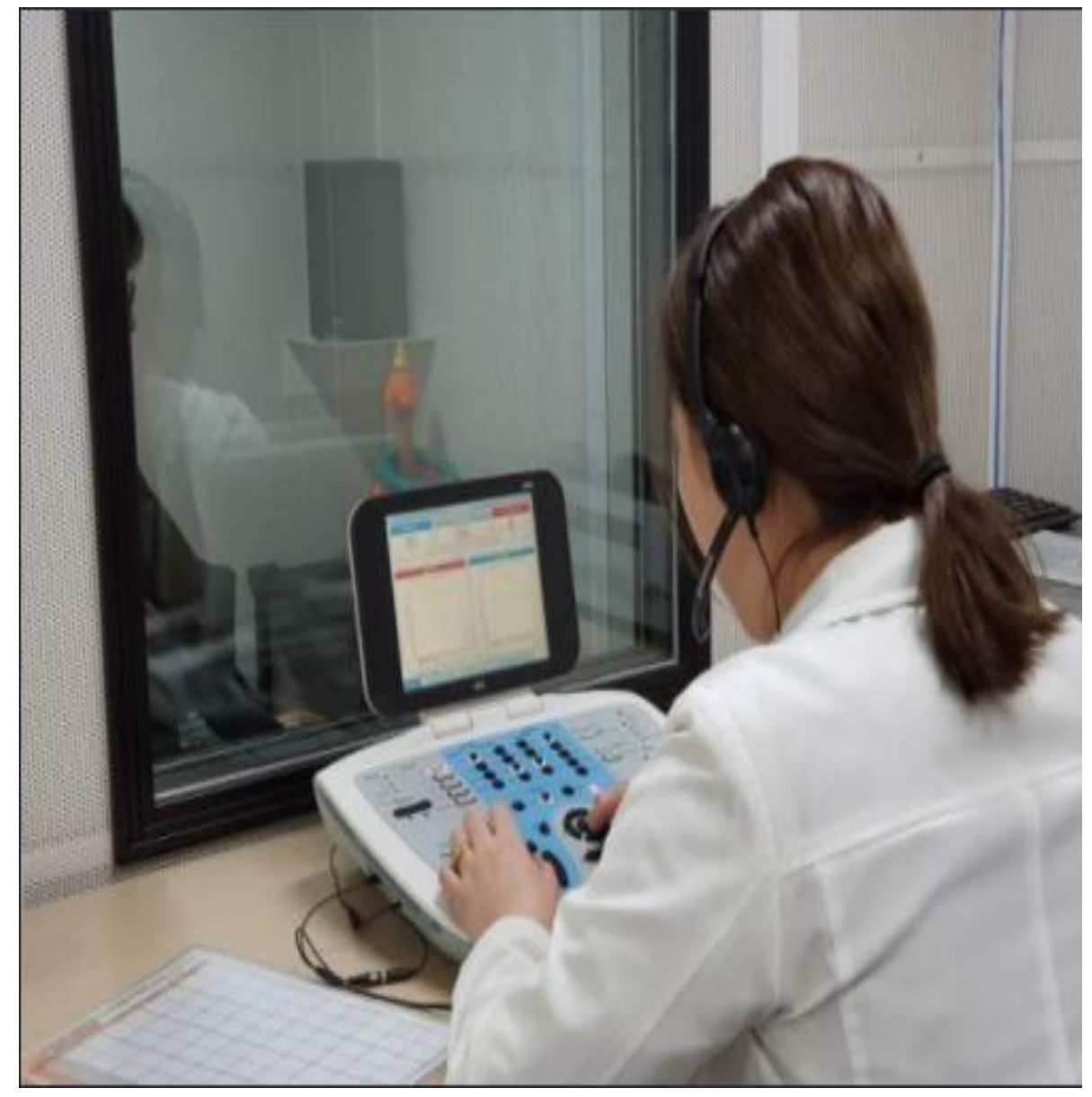

Figure 8. An experimenter undergoing a hearing test in a silent room. 


\section{Experimental and Results}

The measurements in Table 3 show that 10 out of 12 subjects were diagnosed with normal hearing and two were partially hearing impaired. Due to the nature of hearing thresholds by age group, they can be heard better when the frequency is lower than when the frequency is high.

Sound hearing measurements were made once more for subjects suspected of partial hearing damage, and the seventh subject recognized the number of pulse tones normally. After explaining to subjects how to self-identify this new hearing measurement method and asking them to judge partial hearing loss on their measurement results, everyone agreed that it was consistent with the results of self-hearing impairment.
Table 3. Measurement results

\begin{tabular}{|c|c|c|c|c|}
\hline persons & ages & sex & no. of pulse tones & $\begin{array}{c}\text { hearing } \\
\text { damage? }\end{array}$ \\
\hline 1 & 15 & 여 & 9,9 & \\
\hline 2 & 14 & 여 & 9,9 & \\
\hline 3 & 12 & 여 & 9,9 & \\
\hline 4 & 12 & 여 & 9,9 & \\
\hline 5 & 28 & 남 & 9,9 & \\
\hline 6 & 27 & 남 & 9,9 & \\
\hline 7 & 46 & 남 & 9,8 & 2nd=ok \\
\hline 8 & 43 & 남 & 8,8 & 2nd=no \\
\hline 9 & 45 & 여 & 9,9 & \\
\hline 10 & 45 & 여 & 8,9 & \\
\hline 11 & 23 & 남 & 8,9 & \\
\hline 12 & 22 & 남 & 8,9 & \\
\hline
\end{tabular}




\section{Conclusion}

In this study, to cope quickly and easily from the initial stage of hearing impairment, we propose a new method of compensation for partial bandages of both ears, which self-determines hearing impairment by the number of pulse tones.

In an experiment with 12 subjects, one person was identified as suspected of partial hearing damage, and the subjects themselves were already aware of it.

It has been confirmed that the proposed method can measure hearing easily, quickly, and cheaply using APP in an online environment. Now, through the spread of the proposed hearing measurement method, it is expected that it will help individuals live a healthy life by easily determining whether their hearing is damaged or not. 


\section{Thank you}

rm 